\title{
Pengaruh Partisipasi Anggaran Terhadap Kinerja Manajerial Pada PT. Bina Avia Persada
}

\author{
Devis Lucky Pakasi
}

\author{
Fakultas Ekonomi Jurusan Akuntansi \\ Universitas Sam Ratulangi Manado. \\ Email :lucky.devisp@gmail.com
}

\begin{abstract}
Influence of budget participation has attracted the attention of researchers in recent years. Some research on the relationship of budget participation on managerial performance indicates inconsistent results. This study aims to prove the existence and how the influence of budget participation on managerial performance.The object in this research is PT. Avia Bina Persada in the company is engaged in the scope of the airlines that provide short pelatian for prospective flight attendants and staff of the airlines. For the data used in this study was obtained from the perception of employees and corporate leaders involved in the preparation of the budget, including middle managers and ordinary employees lower managers. Data obtained through questionnaires to 20 employees and 10 managers with a total questionnaires were distributed to 30 sheets. The analysis model is a simple linear regression. The result is that the PT. Avia Bina Persada, a positive effect of budget participation on managerial performance. That is, the higher the participation, the budget will be higher the managerial performance.
\end{abstract}

Keywords : participation budget,performance

\section{PENDAHULUAN}

\section{Latar Belakang Masalah}

Perusahaan sebagai suatu unit kesatuan yang terintegrasi, dengan tujuan menghasilkan laba dewasa ini dituntut untuk dapat bersaing dalam lingkungan bisnis. Agar dapat bersaing, perusahaan harus melaksanakan fungsi-fungsi dalam manajemen, terutama fungsi perencanaan. "perencanaan merupakan tindakan yang dibuat berdasarkan fakta dan asumsi mengenai gambaran kegiatan yang dilakukan pada waktu yang akan datang dalam mencapai tujuan yang diinginkan". Komponen penting dalam fungsi perencanaan adalah dengan membuat anggaran.

Menurut Hansen dan Mowen (2009), "anggaran adalah suatu rencana kuantitatif dalam bentuk moneter maupun nonmoneter yang digunakan untuk menerjemahkan tujuan dan strategi perusahaan dalam satuan operasi”. Oleh karena pentingnya anggaran dalam suatu perusahaan, dibutuhkan penyusunan anggaran yang baik. Anggaran yang disusun hendaknya dapat mengakomodir kepentingan setiap departemen yang terkait dalam pelaksanaannya. Untuk itu diperlukan partisipasi dalam penyusunan anggaran oleh berbagi pihak dalam perusahaan. Baik dari manajemen tingkat atas (top level management) maupun manajemen tingkat bawah (lower level management). Pihak-pihak inilah yang akan memainkan peranan penting dalam mempersiapkan dan mengevaluasi berbagai alternatif dari partisipasi dalam proses penyusunan anggaran.

PT Bina Avia Persada yang bertempat di kompleks Ruko Mega Smart Blok 9 No 5 Jl. Piere Tendean, Boulevard Manado adalah perusahaan yang bergerak di bidang jasa, 
khususnya dalam penerbangan yang melatih profesi untuk Pramugari dan Staff Airlines, yang mempunyai karyawan 35 orang, perusahaan ini bergantung pada devisi promosi yang harus dapat bekerja dengan baik, karena divisi promosi sebagai pusat laba, dan juga dengan divisi - divisi yang lain juga ada kebutuhan yang harus di penuhi untuk kelancaran, mereka harus dapat di penuhi. Saat fenomena itu terjadi, yang pertama sekali menghadapi kendala, tentu saja para karyawan dan manajer bawah. Anggaran yang telah disusunpun tidak dapat terwujud. Namun, apakah mereka secara individu ikut bertanggung jawab?. Para karyawan dan manajer bawah yang terlibat secara langsung dengan dampak fenomena tersebut tentu saja memiliki pengalaman dan pengetahuan tentang hal-hal semacam itu. Untuk itu, saat anggaran berikutnya dibuat, partisipasi mereka tentu sangat diperlukan agar dapat menghasilkan anggaran yang tepat dan menimbulkan rasa tanggung jawab di setiap individu. Memperhatikan betapa pentingnya partisipasi dalam penyusunan anggaran, dan bagaimana pengaruhnya terhadap kinerja manajerial, peneliti menetapkan judul : " Pengaruh Partisipasi Anggaran Terhadap

\section{Kinerja Manajerial Pada PT. Bina Avia Persada. “}

\section{Perumusan masalah}

Dari uraian di atas, maka penulis merumuskan masalah sebagai berikut. : "Apakah partisipasi dalam penyusunan anggaran berpengaruh terhadap kinerja manajerial pada PT. Bina Avia Persada? “

\section{Tujuan Penelitian}

Secara umum tujuan penelitian ini adalah untuk membuktikan pengaruh partisipasi dalam penyusunan anggaran terhadap kinerja manajerial. Sesuai dengan latar belakang yang peneliti kemukakan dan perumusan masalah maka penelitian ini bertujuan untuk membuktikan apakah ada pengaruh antara partisipasi anggaran dengan kinerja manajerial pada PT. Bina Avia Persada

\section{Manfaat Penelitian}

1. Bagi peneliti penelitian ini bermanfaat dalam memperdalam pengetahuan peneliti di bidang akuntansi manajemen dan sistem pengendalian manajemen khususnya mengenai hubungan partisipasi penyusunan anggaran dan kinerja manajerial.

2. Bagi PT. Bina Avia Pesada, khususnya untuk pihak manajemen. Penelitian Ini diharapkan menjadi bahan referensi dan informasi sebagai bahan pertimbangan untuk menerapkan partisipasi anggaran lebih efektif untuk peningkatan kinerja manajerial.

3. Bagi pihak lain, penelitian ini diharapkan dapat menjadi bahan referensi dalam penelitian-penelitian selanjutnya yang sejenis.

\section{TINJAUAN PUSTAKA}

\section{Pengertian Anggaran}

Dalam pengelolahan perusahaan, manajemen menetapkan tujuan (goals) dan sasaran (objectives) dan kemudian membuat rencana kegiatan untuk mencapai tujuan dan sasaran tersebut. Secara umun manajemen dapat di artikan sebagai suatu proses yang terdiri dari perencanaan, pengorganisasian, pengarahan, dan pengendalian maka planning merupakan fungsi yang memengang peranan yang sangat penting karena merupakan dasar bagi pelaksanaan fungsi-fungsi yang lain. Penganggaran (budgeting) menunjukan suatu proses sejak tahap persiapan yang diperlukan sebelum dimulainya penyusunan rencana pengumpulan berbagai data dan informasi yang perlu, pembagian tugas perencanaan, penyusunan rencana sendiri, implementasi dari rencana tersebut, sampai pada akhir tahap pengawasan dan evaluasi dari hasil rencana itu. Hasil dari kegiatan penganggaran (budgeting) adalah anggaran (budget). Anggaran adalah suatu rencana 
terinci yang dinyatakan secara formal dalam ukuran kuatitatif, biasanya dinyatakan dalam satuan uang, untuk perolehan dan penggunaan sumber-sumber suatu organisasi dalam jangka waktu tertentu, biasanya satu tahun. Haruman dan Rahayu (2007).

\section{Klasifikasi Anggaran}

Menurut Tendi Haruman dan Sri Rahayu (2007) menyatakan klasifikasi anggaran dibagi berdasarkan :

1. Berdasarkan ruang lingkup

2. Berdasarkan Fleksibilitasnya

3. Berdasarkan Jangka Waktu

Fungsi Anggaran

Menurut Prof Slamet Sodikin (2015). Beberapa fungsi anggaran dalam proses manajemen adalah sebagai berikut :

1. Alat Perencanaan

Penganggaran merupakan wahana bagi para manajer untuk menentukan rencana kegiatan perusahaan secara menyeluru

2. Alat Koordinasi

Sebagai alata koordinasi, penganggaran Merupaka proses Penyelarasan Untuk rencana Antar bagian

3. Alat Pengawasan Dan Pengendalian

Sebagai pengawasan, anggaran menjadi alat untuk membuat realitas tidak menyimpang secara tidak menguntungkan dari angka-angka yang tercantum dalam anggaran

4. Dasar Penilaian Kinerja

Anggaran juga berfungsi sebagai dasar untuk menilai kinerja manajer

\section{Penyusunan Anggaran}

Menurut R.A Supriyono yang di kutip oleh Tendi Haruman dan Sri Rahayu (2007) penyusunan anggaran adalah proses penentuan peran setiap manajer atau karyawan dalam melaksanakan program atau bagian program.

\section{Prinsip Penyusunan Anggaran}

Menurut Tendi Haruman dan Sri Rahayu (2007) menyatakan bahwa prinsip-prinsip dasar yang harus dipenuhi dan ditaati agar suatu anggaran dapat disusun dan dilaksanakan sesuai dengan rencana adalah sebagai berikut:
1. Management Involvement
2. Organizational Adaption
3. Responcibility Accounting
4. Full Communication
5. Timeliness

\section{Pengertian Partisipasi}

Menurut R.A Supriyono yang di kutip oleh Tendi Haruman dan Sri Rahayu (2007) partisipasi anggaran adalah manejer setiap pusat pertanggujawaban mempunyai kesempatan untuk meyelaskan dan memberikan mengenai anggaran yang akan disusun. Dalam menyusun anggaran harus diperhatikan implkasi atau keterlibatan aspek perilaku manusia. Kesuksesan anggaran hanya dapat dicapai ketika semua pelaksana secara simpatik mau membantu dalam melasksanakan anggaran.

\section{Kinerja Manajerial}

Kinerja perusahaan adalah tingkat pencapaian hasil dalam rangka mewujudkan tujuan perusahaan. Kinerja manajerial adalah kinerja individu anggota organisasi dalam kegiatan-kegiatan manajerial Tubagus Dradjat (2015). Kinerja manajerial merupakan hasil dari proses aktivitas manajerial yang efektif mulai dari proses perencanaan, pelaksanaan, penatausahaan, laporan pertanggung jawaban, pembinaan, dan pengawasan. 
Selanjutnya kinerja manajerial adalah seberapa efektif dan efisien manajer telah bekerja untuk mencapai tujuan organisasi. seseorang yang memegang posisi manajerial diharapkan mampu menghasilkan suatu kinerja manajerial. Berbeda dengan kinerja karyawan umumnya yang bersifat konkrit, kinerja manajerial bersifat abstrak dan kompleks. Manajer menghasilkan kinerja dengan mengarahkan bakat dan kemampuan, serta usaha beberapa orang lain yang ada didalam daerah wewenangnya. Kinerja manajerial merupakan suatu faktor yang dapat meningkatkan keefektifan suatu organisasi.

\section{Tujuan Manajemen Kinerja}

Tujuan-tujuan manajemen kinerja ada tiga macam : Stategis, administasi dan pengembangan, Noe, Hollenbeck, Gerhart dan Wright (2011)

1. Tujuan Strategis

2. Tujuan Administrasi

3. Tujuan Pengembangan

\section{METODE PENELITIAN}

Jenis Data

Jenis data yang digunakan dalam penelitian ini berupa data kualitatif yang terdiri dari data primer dan data sekunder.

\section{a. Data Primer}

Menurut Istijanto yang di kutip oleh Danang Sunyoto (2013) Data Primer adalah data asli yang dikumpulkan sendiri oleh peneliti untuk menjawab masalah penelitiannya secara khusus. Data Primer penelitian ini di ambil berdasarakan dari hasil kuesioner yang telah diisi oleh manejer dan karyawan yang ada di Bina Avia Persada.

b. Data Sekunder

Data Sekunder menurut Danang Sunyoto (2013) adalah data yang bersumber dari catatan yang ada pada perusahaan dan sumber lain. Data sekunder penelitian ini adalah sejarah singkat perusahaan.

\section{Metode Pengambilan Data}

Langkah-langkah pengambilan data primer atau pengiriman kuesioner adalah sebagi berikut :

1. Kuesioner dikirim kepada semua anggota populasi.

2. Setelah 1 minggu, peneliti mengumpulkan kuesioner yang telah diisi responden.

3. Jika ada responden yang belum mengembalikan daftar pertanyaan tersebut, maka kepada mereka diberi waktu 1 minggu lagi.

4. Setelah batas waktu yang ditentukan dan kuesioner telah dikembalikan oleh responden, maka peneliti akan mengolah data jika jumlah data yang terkumpul sudah 30, tetapi jika data belum mencukupi, maka akan dicoba kembali untuk mengirimkan kuesioner kepada responden yang belum mengembalikan

\section{Uji Kualitas Data} kuesioner tersebut.

1. Uji Validasi

a) Menggunakan tanda flag (*) di mana tanda satu buah flag (*) menunjukkan bahwa indikator tersebut signifikan pada taraf 5\% dan tanda dua buah flag $(* *)$ menunjukkan bahwa indikator tersebut valid pada taraf $1 \%$.

b) Menggunakan signifikansi pada baris kedua masing-masing indikator di mana indikator dinyatakan valid pada taraf 5\% jika mempunyai signifikansi di bawah 0,05 dan valid pada taraf $1 \%$ jika mempunyai signifikansi di bawah 0,01 . 
1. Uji Reliabilitas

Menurut Danang Sunyoto (2013) reliabilitas adalah alat untuk mengukur suatu kuesioner yang merupakan indikator dari variabel atau konstruk. Untuk melihat reliabilitas masing-masing instrument yang digunakan, peneliti mengunakan koefisen cronbach alpha, Cronbach alpha yang baik adalah yang semakin mendekati 1 " reliabilitas yang kurang dari 0,6 adalah kurang baik, 0,7 dapat diterima dan reliabilitas dengan cronbach's alpha 0.8 atau lebih adalah baik". Pengujian reliabilitas dilakukan dengan mengunakan program SPSS versi 17.

\section{Uji Asumsi Klasik}

Penggunaan analisis regrasi dalam statistik harus bebas dari asumsi-asumsi klasik seperti normalitas data, autokorelasi, heterokedasitas dan asumsi-asumsi klasik lainnya. Untuk menguji hal tersebut peneliti juga mengunakan program SPSS versi 17.

1. Uji Normalitas Data

Menurut central limit theorem, yang dikutip oleh Siregar asumsi normalitas akan terpenuhi apabila jumlah sampel yang digunakan lebih dari atau sama dengan 25. Seperti pada uji beda biasa, jika signifikansi di bawah 0,05 berarti terdapat perbedaan yang signifikan, dan jika signifikansi di atas 0,05 maka tidak terjadi perbedaan yang signifikan. Penerapan pada uji Kolmogorov Smirnov adalah bahwa jika signifikansi di bawah 0,05 berarti data yang akan diuji mempunyai perbedaan yang signifikan dengan data normal baku, berarti data tersebut tidak normal.

2. Uji Autokorelasi

Persamaan regresi yang baik adalah tidak memiliki masalah autokorelasi, jika terjadi autokorelasi maka persamaan tersebut menjadi tidak baik atau tidak layak dipakai prediksi. Masalah autokorelasi baru timbul jika ada korelasi secara linier antara kesalahan penganggu dengan kesalahan penganggu peride sebelumnya, Danang Sunyoto (2013)

3. Uji Heteroskedastisitas

Dalam persamaan regresi perlu juga diuji mengenai sama atau tidak varian dari residual dari observasi yang satu dengan observasi dengan yang lain, jika residual mempunya varian yang sama disebut terjadi homokedastisitas dan varian tidak sama atau berbeda disebut hereoskedastisitas, Danang Sunyoto (2013). Uji Glejser dilakukan dengan cara meregresikan antara variabel independen dengan nilai absolute residualnya. Jika nilai signifikansi antara variabel independen dengan absolute residual lebih dari 0,05 maka tidak terjadi masalah heteroskedastisitas.

\section{Teknik Analisis Data}

Untuk menguji hipotesis, metode analisis data yang digunakan adalah analisa regresi linier sederhana, karena menyangkut sebuah variabel independen dan sebuah variabel dependen. Disamping itu, metode analisis ini digunakan untuk melihat hubungan antara kedua variabel tersebut. Model persamaan regresi untuk menguji hipotesis, dengan formulasi sebagai berikut: 


\title{
$\mathbf{Y}=\boldsymbol{\alpha}+\boldsymbol{\beta} \mathbf{X}+$
}

\author{
Keterangan : \\ $\mathrm{Y}=$ Kinerja Manajerial \\ $\alpha=$ Konstanta \\ $\mathrm{X}=$ Partisipasi anggaran \\ $\beta=$ Koefisien arah regresi \\ $\varepsilon=$ Tingkat kesalahan pengganggu
}

\section{Pengujian Hipotesis}

Hipotesis penelitian diuji dengan menggunakan analisa regresi sederhana. Pengujian hipotesis ditujukan untuk menguji ada tidaknya pengaruh dari variabel bebas secara keseluruhan terhadap variabel dependen. Dari hasil pengolahan data dengan program SPSS release 17, dapat diperoleh hasil dari Regresi yang terdiri dari Model Summary, Anova, dan Coefficients. Dari hasil tersebut kemudian dilakukan analisa untuk memperoleh jawaban hipotesis apakah diterima atau ditolak. Dengan menggunakan data analisis ini dimaksudkan untuk membuktikan apakah variabel independen akan berinteraksi dengan variabel dependen yaitu kinerja manajerial. Pengaruh variabel independen terhadap variabel dependen akan diuji dengan tingkat signifikansi $\alpha \leq 0,05$. Apabila hasil signifikansi pada tabel $\mathrm{t} \geq 0,05$ maka Ho $: \rho=0$ (partisipasi anggaran tidak berpengaruh terhadap kinerja manajerial). Sedangkan jika hasil signifikansi pada tabel $\mathrm{t} \leq$ 0,05 , maka Ho : $\rho \neq 0$ (partisipasi anggaran berpengaruh pada kinerja manajerial).

\section{HASIL PENELITIAN DAN PEMBAHASAN}

1. Statistic Deskriptif

Tabel

\section{Hasil Statistik Deskriptif}

\begin{tabular}{|l|r|r|r|r|r|r|r|}
\hline & $\mathrm{N}$ & Min & Max & \multicolumn{1}{|c|}{ Sum } & Mean & Std. Deviation & Variance \\
\hline Partisipasi Anggaran & 30 & 7.00 & 42.00 & 691.00 & 23.0333 & 10.15223 & 103.068 \\
Kinerja manajerial & 30 & 9.00 & 56.00 & 1128.00 & 37.6000 & 11.90943 & 141.834 \\
Valid N (listwise) & 30 & & & & & & \\
\hline
\end{tabular}

Sumber : Data hasil olahan 2015

Berdasarkan jawaban dari 30 responden maka hasil pengukuran variabel partisipasi anggaran mempunyai total jawaban selurunya berjumlah 691 dengan jawaban terendah 7 dan jawaban tertinggi 42 sehingga di peroleh skor jawaban ratarata (mean) 23.033 dengan standar deviasi 10.152.

Hasil pengukuran variabel kinerja manajerial pada tabel terlihat, dari 30 respoden di peroleh total jawaban selurunya 1128 dengan jawaban terendah 9 dan jawaban tertinggi 56 sehingga di peroleh skor jawaban responden mempunyai ratarata(mean) 37,6 dengan standar deviasi 11.909. hal ini berarti tidak ada manajer yang menjadi responden yang mempunyai kinerja pada tingkat ekstrim. 


\section{Hasil Uji Kualitas Data}

Tabel

Reliability Statistik

Partisipasi Anggaran

\begin{tabular}{|r|r|}
\hline $\begin{array}{c}\text { Cronbach's } \\
\text { Alpha }\end{array}$ & N of Items \\
\hline .969 & 6 \\
\hline
\end{tabular}

Sumber : Data hasil olahan 2015

Berdasarkan tabel hasil pegolahan data, menunjukan bahwa variabel partisipasi anggaran adalah reliabel dengan cronbach alpa 0,969, yang berarti bahwa 0,969 >0.60, berdasarkan hasil ini juga dapat disimpulkan item pertanyaan kuesioner sudah memiliki reliabilitas yang tinggi.

Tabel

Validitas Instrumen Pertanyaan Partisipasi Anggaran

\begin{tabular}{|l|l|r|r|r|r|r|r|r|}
\hline & & \multicolumn{1}{|c|}{$\mathrm{x} 11$} & \multicolumn{1}{c|}{$\mathrm{x} 12$} & $\mathrm{x} 13$ & \multicolumn{1}{c|}{$\mathrm{x} 14$} & $\mathrm{x} 15$ & $\mathrm{x} 16$ & \multicolumn{1}{c|}{$\mathrm{x} 1$} \\
\hline $\mathrm{x} 11$ & Pearson Correlation & 1 & $.848^{* *}$ & $.829^{* *}$ & $.759^{* *}$ & $.851^{* *}$ & $.786^{* *}$ & $.903^{* *}$ \\
\hline $\mathrm{x} 12$ & Pearson Correlation & $.848^{* *}$ & 1 & $.862^{* *}$ & $.827^{* *}$ & $.829^{* *}$ & $.849^{* *}$ & $.929^{* *}$ \\
\hline $\mathrm{x} 13$ & Pearson Correlation & $.829^{* *}$ & $.862^{* *}$ & 1 & $.921^{* *}$ & $.848^{* *}$ & $.877^{* *}$ & $.957^{* *}$ \\
\hline $\mathrm{x} 14$ & Pearson Correlation & $.759^{* *}$ & $.827^{* *}$ & $.921^{* *}$ & 1 & $.841^{* *}$ & $.857^{* *}$ & $.935^{* *}$ \\
\hline $\mathrm{x} 15$ & Pearson Correlation & $.851^{* *}$ & $.829^{* *}$ & $.848^{* *}$ & $.841^{* *}$ & 1 & $.840^{* *}$ & $.932^{* *}$ \\
\hline $\mathrm{x} 16$ & Pearson Correlation & $.786^{* *}$ & $.849^{* *}$ & $.877^{* *}$ & $.857^{* *}$ & $.840^{* *}$ & 1 & $.934^{* *}$ \\
\hline $\mathrm{x} 1$ & Pearson Correlation & $.903^{* *}$ & $.929^{* *}$ & $.957^{* *}$ & $.935^{* *}$ & $.932^{* *}$ & $.934^{* *}$ & 1 \\
\hline
\end{tabular}

Sumber : Data hasil olahan 2015

Berdasarkan tabel pada barisan $\mathrm{x} 1$ hasil korelasi betanda (**), menunjukan bahwa indikator instrumen tersebut valid, karena hasil output pada x1 semuanya bertanda (**), dengan kata lain semua indikator yang ada pada $\mathrm{x} 1$ semuanya valid. Untuk menguji validitas, butir pertanyaan tersebut juga dibandingkan dengan $\mathrm{r}$ tabel pada 0,05 derajat kebebasan atau 5\% derajat kebebasan. Pada signifikasi $5 \%$ derajat kebebsan $\mathrm{df}=28$, jumlah (kasus-2), $\mathrm{r}$ tabel sebesar 0,361. Berdasarkan tabel 4.3 pada baris $\mathrm{x} 1$, hasil uji validitas menunjukan semua pertanyaan valid karena $r$ hitung $>r$ tabel pada taraf signifikas $5 \%$.

Tabel

Reliability Statistik

Kinerja Manajerial

\begin{tabular}{|r|r|}
\hline $\begin{array}{c}\text { Cronbach's } \\
\text { Alpha }\end{array}$ & N of Items \\
\hline .977 & 8 \\
\hline
\end{tabular}

Sumber : Data hasil olahan 2015

Berdasarkan tabel hasil pengelolahan data, menunjukan bahwa reliabilitas variabel kinerja manajerial adalah reliabel dengan cronbach alpa 0,977 yang berarti 0,977 $>0,60$, berdasarkan hasil ini juga dapat disimpulkan item pertanyaan kuesioner sudah memiliki reliabilitas yang tinggi. 
Tabel

Validitas Instrumen Pertanyaan Kinerja Manajerial

\begin{tabular}{|c|c|c|c|c|c|c|c|c|c|c|}
\hline & & y11 & y12 & y13 & y14 & $\mathrm{y} 15$ & y16 & y17 & y18 & $\mathrm{y} 1$ \\
\hline y11 & Pearson Correlation & 1 & $.889^{\text {** }}$ & $.901^{\text {*** }}$ & $.873^{* * *}$ & $837^{* *}$ & $.861^{* *}$ & $.847^{* *}$ & $.834^{* *}$ & $.946^{* *}$ \\
\hline y12 & Pearson Correlation & $.889^{* *}$ & 1 & $.846^{* *}$ & $.802^{* *}$ & $.810^{* *}$ & $.775^{* *}$ & $.768^{* * *}$ & $.862^{* *}$ & $.906^{* *}$ \\
\hline y13 & Pearson Correlation & $.901^{* * *}$ & $.846^{* *}$ & 1 & $.800^{* * *}$ & $.851^{* *}$ & $.813^{* *}$ & $.813^{* *}$ & $.760^{* *}$ & $.913^{* *}$ \\
\hline y14 & Pearson Correlation & $.873^{* * *}$ & $.802^{* * *}$ & $.800^{* * *}$ & 1 & $.818^{* *}$ & $.933^{* *}$ & $.866^{* *}$ & $.867^{* *}$ & $.936^{* *}$ \\
\hline $\mathrm{y} 15$ & Pearson Correlation & $.837^{* * *}$ & $.810^{\text {** }}$ & $.851^{\text {** }}$ & $.818^{* *}$ & 1 & $.850^{* *}$ & $.888^{* *}$ & $.816^{* *}$ & $.926^{* *}$ \\
\hline y16 & Pearson Correlation & $.861^{* * *}$ & $.775^{* *}$ & $.813^{* *}$ & $.933^{* *}$ & $.850^{* *}$ & 1 & $.904^{* *}$ & $.875^{* *}$ & $.943^{* *}$ \\
\hline y17 & Pearson Correlation & $.847^{* *}$ & $.768^{* *}$ & $.813^{* *}$ & $.866^{* * *}$ & $.888^{* *}$ & $.904^{* *}$ & 1 & $.863^{* *}$ & $.937^{* *}$ \\
\hline y18 & Pearson Correlation & $.834^{* * *}$ & $.862^{* * *}$ & $.760^{* *}$ & $.867^{* *}$ & $.816^{* *}$ & $.875^{* *}$ & $.863^{* *}$ & 1 & $.925^{* *}$ \\
\hline $\mathrm{y} 1$ & Pearson Correlation & $.946^{* * *}$ & $.906^{* *}$ & $.913^{* *}$ & $.936^{* *}$ & $.926^{* *}$ & $.943^{* *}$ & $.937^{* *}$ & $.925^{* *}$ & 1 \\
\hline
\end{tabular}

Sumber : Data hasil olahan 2015

Berdasarkan table hasil pengolahan data, pada baris y1 hasil korelasi betanda (**), yang menunjukan bahwa indikator instrumen tersebut valid, dengan kata lain semua indikator yang ada pada y1 adalah valid. Berdasarkan tabel 4.4 terlihat bahwa hasil uji validitas menunjukan semua pertanyaan valid karena $r$ hitung $>\mathrm{r}$ tabel pada taraf signifikasi $5 \%$.

\section{Hasil Uji Asumsi Klasik}

a. Uji Normalitas

Tabel

\section{Uji Normalitas}

\begin{tabular}{|l|r|r|r|r|r|r|}
\hline & \multicolumn{3}{|c|}{ Kolmogorov-Smirnov $^{\mathrm{a}}$} & \multicolumn{3}{c|}{ Shapiro-Wilk } \\
\hline & Statistic & df & \multicolumn{1}{c|}{ Sig. } & Statistic & \multicolumn{1}{c|}{ Df } & \multicolumn{1}{c|}{ Sig. } \\
\hline $\begin{array}{l}\text { Unstandardized } \\
\text { Residual }\end{array}$ & .136 & 30 & .161 & .938 & 30 & .082 \\
\hline
\end{tabular}

a. Lilliefors Significance Correction

Sumber : Data hasil olahan 2015

Berdasarkan tabel (Test of Normality) hasil pengelolahan data, dapat dilihat pada kolom sig sebesar 0.161, lebih besar dari 0,05 maka penelitian ini tidak terjadi perbedaan yang signifikan.

b. Uji Autokorelasi

Tabel

Hasil Uji Autokorelasi

\begin{tabular}{|l|r|}
\hline Model & Durbin-Watson \\
\hline 1 & $2.339^{\mathrm{a}}$ \\
\hline
\end{tabular}




\author{
a. Predictors: (Constant), \\ Partisipasi Anggaran \\ b. Dependent Variable: Kinerja \\ Manajerial \\ Sumber : Data hasil olahan 2015
}

Berdasarkan tabel koefisien Durbin-Watson sebesarnya 2,339, atau lebih besar dari 2. Dengan demikian, dapat disimpulkan bahwa dalam regresi antara variabel partisipasi anggaran pada kinerja manajerial tidak terdapat autokorelasi positif pada model regresi.

c. Uji Heteroskedastisitas

Tabel

Hasil Uji Heteroskedastisitas

Coefficients $^{a}$

\begin{tabular}{|c|c|c|c|c|c|c|}
\hline & \multirow{2}{*}{ Model } & \multicolumn{2}{|c|}{$\begin{array}{l}\text { Unstandardized } \\
\text { Coefficients }\end{array}$} & \multirow{2}{*}{$\begin{array}{c}\text { Standardized } \\
\text { Coefficients } \\
\text { Beta }\end{array}$} & \multirow{2}{*}{$\mathrm{t}$} & \multirow{2}{*}{ Sig. } \\
\hline & & B & $\begin{array}{l}\text { Std. } \\
\text { Error }\end{array}$ & & & \\
\hline \multirow[t]{2}{*}{1} & (Constant) & 5.214 & 2.377 & & 2.193 & .037 \\
\hline & $\mathrm{x} 1$ & .020 & .095 & .039 & .207 & .838 \\
\hline
\end{tabular}

a. Dependent Variable: ar

Sumber : Data hasil olahan 2015

Berdasarkan tabel hasil pengolahan data, menunjukkan tidak ada gangguan heteroskedastisitas yang terjadi dalam proses estimasi parameter model penduga, dimana tidak ada nilai t hitung yang signifikan atau nilai signifikan (sig) lebih dari 0,05 ( $p>0,05$ ). Jadi secara keseluruhan dapat disimpulkan bahwa tidak ada masalah heteroskedastisitas.

\title{
Hasil Pengujian Hipotesis
}

\section{Table}

\section{Model Summary}

\begin{tabular}{|l|r|r|r|r|}
\hline Model & R & R Square & \multicolumn{1}{c|}{$\begin{array}{c}\text { Adjusted R } \\
\text { Square }\end{array}$} & $\begin{array}{c}\text { Std. Error of the } \\
\text { Estimate }\end{array}$ \\
\hline 1 & $.764^{\mathrm{a}}$ & .583 & .568 & 7.82599 \\
\hline
\end{tabular}

a. Predictors: (Constant), Partisipasi Anggaran

b. Dependent Variable: Kinerja Manajerial

Sumber : Data hasil pengolahan 2015

Berdasarkan tabel (model summary) hasil pegolahan data, dapat kita lihat hasil analisi regresi secara keseluruhan menunjukan $\mathrm{R}^{2}$ sebesar 0.764 yang berarti bahwa hubungan antara partispasi anggaran dengan kinerja manajerial mempunyai hubungan yang kuat yaitu $76.4 \%$. dikatakan kuat, karena angka tersebut di atas 0.5 atau diatas $50 \%$. Sedangkan nilai R Square atau nilai koefisien determinasi sebesar 0.583, yang berarti 
bahwa variabel independen (kinerja manajerial) mampu dijelaskan oleh variabel partisipasi anggaran sebesar 58.3\% sedangkan selebihnya $42.7 \%$ dapat dijelaskan oleh faktor-faktor lain yang tidak diikutsertakan dalam penelitian ini.

Tabel

\section{Coefficients}

\begin{tabular}{|l|r|r|r|r|r|}
\hline \multirow{2}{*}{ Model } & \multicolumn{2}{|c|}{$\begin{array}{c}\text { Unstandardized } \\
\text { Coefficients }\end{array}$} & $\begin{array}{l}\text { Standardized } \\
\text { Coefficients }\end{array}$ & \multirow{2}{*}{$\mathrm{t}$} & \multirow{2}{*}{ Sig. } \\
\cline { 2 - 5 } & \multicolumn{1}{|c|}{ B } & \multicolumn{1}{|c|}{ Std. Error } & \multicolumn{1}{|c|}{ Beta } & & \\
\hline (Constant) & 16.968 & 3.593 & & 4.722 & .000 \\
\hline $\begin{array}{l}\text { Partisipasi } \\
\text { Anggaran }\end{array}$ & .896 & .143 & .764 & 6.258 & .000 \\
\hline
\end{tabular}

a. Dependent Variable: Kinerja Manajerial

Sumber : Data hasil pengolahan 2015

Berdasarkan tabel hasil pengolahan data, pada kolom unstandardized coefficients bagian B diperoleh model persamaan regresi linier sebagai berikut :

\section{Kinerja manajerial $=16,968+0,896$ Partisipasi anggaran}

Hal ini berarti, apabila variabel partisipasi anggaran diabaikan maka variabel kinerja manajerial sebesar 16,968, dan jika variabel partisipasi anggaran naik sebesar 1 satuan score maka variabel kinerja manajerial meningkat sebesar 0,896. Selain itu berdasarkan tabel 4,10 hasil pengelolahan data, menunjukan bahwa konstanta dan variabel independen (partisipasi anggaran) mempunyai angka signifikan jauh di bawah 0.05 ( 0,000 untuk konstanta dan 0.000 untuk variable independen), dalam hal ini Ho ditolak (partispasi anggaran tidak berpengaruh terhadap kinerja manajerial) dan menerima $\mathrm{Ha}$ (partisipasi anggaran berpengaruh terhadap kinerja manajerial).

\section{KESIMPULAN DAN SARAN Kesimpulan}

Penelitian ini berhasil membuktikan hipotesis, yaitu partisipasi dalam penyusunan anggaran berpengaruh terhadap kinerja manajerial. Dapat disimpulkan juga bahwa pengaruh partisipasi anggaran terhadap kinerja manajerial menunjukkan pengaruh positif. Artinya, semakin tinggi partisipasi anggaran, maka akan semakin tinggi pula kinerja manajerial. Hal ini dibuktikan dari hasil pengujian hipotesis dengan menggunakan model analisis regresi linier sederhana. Dari hasil analisis diperoleh nilai $\mathrm{R}$ menunjukkan bahwa kemampuan variabel partisipasi anggaran dalam menjelaskan atau memberikan sebagian besar informasi yang dibutuhkan untuk memeprediksi variabel kinerja manajerial yang dapat dijelaskan oleh persamaan regresi sedangkan sisanya dijelaskan oleh variabel lain di luar persamaan model.

\section{Saran}

Untuk mendapatkan hasil yang lebih optimal dan untuk menghindari bisa responden atau rendahnya response rate, maka sebaiknya diusahakan menggunakan metode observasi (pengamatan) langsung kepada objek atau metode eksperimen sebagai pengganti metode kuesioner. Memperluas lingkup penelitian (wilayah penelitian), memperbanyak sampel dan pemilihan sampel yang acak, sehingga hasil penelitian dapat digeneralisasikan dan dapat memberi kontribusi dalam meningkatkan Sebaiknya 
penelitian selanjutnya menambahkan variabel lain sebagai variabel independen maupun variabel moderating, karena kinerja manajerial tidak hanya dapat diukur dengan partisipasi dalam penyusunan anggaran saja.

\section{DAFTAR PUSTAKA}

.Doradjat, Tubagus Achmad. 2015. Konsep-Konsep Dasar Manajemen Personalia Masa Kini, Bandung. PT. Refika Aditama

Haruman, Tendi dan Rahayu, Sri, 2007. Penyusunan Anggaran Perusahaan. Edisi ke dua - Yogyakarta ; Graha Ilmu 2007.

Hansen, Don R, dan Mowen, Maryanne.2009 Akuntansi Manajerial. Penerjemah Deny Arnos Kwary. Selemba Empat..

Sodikin, Slamet Sugiri.2015 Akuntansi Manajemen, Yogyakarta. Sekolah Tinggi Ilmu Manajemen, Edisi Ke Lima.

Siregar, syofian.2014 Statistif Parametrik Untuk Penelitian Kuantitatif Dilengkapi Dengan Perhitungan Manual dan Aplikasi Spss Versi 17. Edisi pertama, Jakarta ; Bumi Aksara.

Samryn L.M.2012 Akuntansi Manajemen, Jakarta. Karisma Putra Utama. 3 Jilid.

Sunyoto, Danang (2013). Metodologi Penelitian Akuntansi ; Editor Gunarsa, Aep. Bandung : PT. Refika Aditama.

Noe, Raymond A, Hollenbeck, John R, Gerhar, Barry, Wright, Patrick M.2011 Manajemen Sumber Daya Manusia:Mencapai Keungulan Bersaing. Jakarta: Selemba Empat, 2011-Cetakan Kedua. 